\title{
Linkage-to-Care Following Community-Based HBV and HCV Screening Among Immigrants from the Washington-Baltimore Metropolitan Area, 2016-2019
}

\author{
Daisy Le 1,4 (D) Annie Coriolan Ciceron ${ }^{1} \cdot{\text { Jane } \mathrm{Pan}^{2} \cdot \text { Hee-Soon Juon }}^{3} \cdot$ Carla J. Berg ${ }^{4} \cdot$ T. Angeline Nguyen $^{2}$. \\ Hai Chi Le ${ }^{2} \cdot$ Y. Tony Yang ${ }^{1,4}$
}

Accepted: 23 December 2021 / Published online: 22 January 2022

(c) The Author(s), under exclusive licence to Springer Science+Business Media, LLC, part of Springer Nature 2022

\begin{abstract}
Understanding characteristics that impact linkage-to-care (LTC) among individuals living with HBV and/or HCV can enhance public health efforts to provide tailored care services to prevent and treat viral hepatitis among immigrants. Using HBV/ HCV screening and LTC data from immigrants (2016-2019), descriptive and logistic regression analyses were conducted to assess (1) the relationship between LTC and sociodemographic factors and (2) factors associated with HBV/HCV LTC. About $87 \%$ of those positive HBsAg had LTC and 52\% had LTC among those with HCVAB and confirmed PCR. Access to care was an important LTC predictor for HBV-LTC: those who had neither health insurance nor primary care provider (PCP) were more likely to have HBV-LTC than those who had either health insurance or PCP $(\mathrm{aOR}=2.95,95 \% \mathrm{CI}=1.32-6.59)$. It is essential to equally provide HBV/HCV LTC support to all immigrants from countries with high prevalence regardless of access to care.
\end{abstract}

Keywords Asian Americans · African Americans · Emigrants and immigrants $\cdot$ Health disparities $\cdot$ Liver diseases

\section{Background}

Hepatocellular carcinoma (HCC), the most common type of primary liver cancer, ranks second worldwide in cancer deaths [1]. Chronic hepatitis B virus (HBV) or hepatitis C virus $(\mathrm{HCV})$ infections contribute to approximately $78.0 \%$ of these cases, with worldwide prevalence of HBV and $\mathrm{HCV}$ infections estimated at 257 million and 71 million, respectively [2]. Death from chronic liver disease occurs in $15.0-25.0 \%$ of individuals living with chronic hepatitis B (CHB), while 20.0-30.0\% may develop severe sequelae,

Daisy Le

daisyle@gwu.edu

1 School of Nursing, The George Washington University, 1919 Pennsylvania NW, Suite 500, Washington, DC 20006, USA

2 Hepatitis B Initiative of Washington DC (HBI-DC), Washington, DC, USA

3 Department of Medical Oncology, Thomas Jefferson University, Philadelphia, PA, USA

4 Milken Institute School of Public Health, The George Washington University, Washington, DC, USA such as cirrhosis, liver failure, or HCC [3]. Incidence of HCC is currently the 5th leading cause of cancer-related death in the United States (US) [4] and projected to rapidly increase to rank 3rd by 2030 [5]. In the US, there are currently up to 5.7 million people who are living with a HBV or HCV infection.

Among US immigrants living with HBV infection, an estimated $58.0 \%$ and $11.0 \%$ individuals are from Asia and sub-Saharan Africa, respectively [6]. Since most infected individuals show little to no symptoms until their liver disease is well advanced, about $65.0 \%$ of CHB-infected adults are unaware of their condition [7]. In combination with cultural, linguistic, and financial barriers, this knowledge gap can increase HBV infection rates-particularly for high-risk groups such as immigrants [6]. With insufficient knowledge of liver cancer prevention and treatment [6], and low rates of HBV screening among adults [6], immigrants are often diagnosed with late-stage cancer, resulting in low survival rates and high mortality rates [6].

Fortunately, therapies are now available to inhibit HBV replication and to prevent or cure $\mathrm{HCV}$ infection, thus significantly reducing the risk of liver cancer related deaths. The Centers for Disease Control and Prevention (CDC) [8] 
recommends HBV vaccination and screening for high-risk individuals, including all immigrants from regions where $\mathrm{HBV}$ prevalence is greater than $2.0 \%$ (endemic area), to treat and prevent new infections. For acute HCV infection, treatment should only be considered if HCV RNA persists after 6 months. Individuals with chronic HCV infection can be cured with 8-12 weeks of oral therapies [9].

In their study, Ramirez et al. found that only $44.0 \%$ of $\mathrm{HBV}$ and $\mathrm{HCV}$ infected individuals were linked-to-care [10]. Linkage-to-care (LTC) was defined as having at least one medical visit documented post-diagnosis [11]. This is thought to be mainly attributed to insufficient counseling at diagnosis, unfamiliarity and difficulty navigating the US health care system, limited English proficiency, transportation, lack of health insurance coverage, and other competing priorities faced by this population [12]. Despite the availability of effective therapies, it is unclear whether treatmenteligible patients in the Washington-Baltimore Metropolitan area are willing to seek and receive treatment, and much is not known about the factors that affect their decision to seek follow-up treatment.

In this study, immigrants were screened for chronic hepatitis at community-based events in the Washington-Baltimore metropolitan area, from 2016 to 2019. Individuals who had tested positive were additionally offered LTC services. While widespread screening may be the first step in liver cancer prevention, understanding the associated characteristics and trends that impact LTC of those living with HBV and $\mathrm{HCV}$ can further enhance current public health efforts to provide tailored care services to prevent and treat viral hepatitis among immigrants.

\section{Methods}

\section{Recruitment and Data Collection}

The data for this study were collected by the Hepatitis B Initiative of Washington, DC (HBI-DC), a nonprofit organization that aims to prevent liver disease caused by viral hepatitis in high-risk groups of immigrants. Cumulatively over the past 4 years, HBI-DC has provided no-cost HBV and HCV testing, vaccination, and treatment LTC services for impacted populations at over 245 community events (e.g., churches, mosques, health fairs and community centers) through strategic collaborations and culturally targeted strategies. This study used cross-sectional data from 8730 immigrants (born outside the US or any of the US territories, age $>18$ years), residing in the Washington-Baltimore metropolitan area screened between January 2016 and December 2019. This research was approved by the George Washington University Institutional Review Board (NCR191911).
The HBI-DC partnered with community members to develop recruitment approaches by adopting communitybased participatory research standards. Local ethnic radio stations and newspapers, and culturally and linguistically oriented flyers displayed at prominent community locations were used to promote the scheduled screening events. At each screening events, health educators, bilingual volunteers, and representatives from community partner organizations were present to provide further information on chronic hepatitis infection and to promote the importance of screening, vaccination, and prompt follow-up treatment care. All consenting adults were asked to complete a standardized intake form providing basic demographics (e.g., date of birth, gender, country of birth, primary language, year of arrival in the US, health care access status) information.

\section{HBV and HCV Screening}

Upon intake form completion, the trained phlebotomists proceeded to administer free on-site HBV and HCV screening. Statuses of hepatitis B surface antigen (HBsAg), hepatitis B surface antibody (anti-HBs), and hepatitis C antibody (anti$\mathrm{HCV}$ ) serologies were obtained through blood draw and submitted to LabCorp for analysis. Within 48-72 $\mathrm{h}$, the results were extracted from LabCorp's online portal and entered into the health electronic system. Individuals were then notified of their results over the phone within $24 \mathrm{~h}$ and via mail within 2-3 weeks. For HCV screening, individuals positive for anti-HCV were additionally tested for reflex quantitative HCV RNA through a reverse transcription polymerase chain reaction assay. The HCV RNA sensitivity threshold was $15 \mathrm{IU} / \mathrm{mL}$. From 2016 and part of 2017, confirmatory tests were not performed for all clients who had a positive $\mathrm{HCV}$ antibody test.

\section{Linkage-to-Care}

The HBI-DC team reviewed the screening results with the participants over the phone, using a standardized flow chart and cascade of questions (see Supplemental File), before mailing it out to them. Individuals who had tested positive for chronic hepatitis, or had no immunity to HBV, were considered referred to care if they were additionally contacted by a care coordinator and referred to programs for either medical follow-up care or locations where the complete vaccination series were being offered at no-cost to the patient. Participants were referred to care through their primary care provider (PCP) for treatment-if they had insurance-or to a provider for discounted services on a sliding scale if they were able to pay out-of-pocket. As needed, care coordinators also assisted participants with scheduling their first appointment. 


\section{Measures}

\section{HBV and HCV Serologic Testing Results}

Participant HBV serologic testing results were categorized into one of the following three groups: (1) HBV infected (positive HBsAg), (2) HBV vulnerable (negative HBsAg and negative anti-HBs), or (3) protected (negative HBsAg and positive anti-HBs). For HCV screening, participant results were classified as follows: (1) HCV exposed (positive anti$\mathrm{HCV}$ ), and (2) negative (negative anti-HCV).

\section{Linkage-to-Care Status}

LTC status was ascertained through follow-up with partnering clinics or self-report during follow-up calls that were conducted 6 months after a participant's initial results counseling call. Regardless of insurance or PCP status, the team attempted to follow up with each participant who opted to receive care and treatment up to three times to confirm that participants have indeed attended their first appointment, calling at varying the days and times. A participant was considered linked to care if they attended at least one HBVdirected medical appointment following initial $\mathrm{HBV}$ or $\mathrm{HCV}$ diagnosis. LTC outcomes were noted in an encrypted Excel database, and used to categorize participants as referred, linked, or not linked to care (participants they were unable to contact).

\section{Control Variables}

Demographic information included in the analysis were age (derived from the date of birth), gender $(0=$ male; $1=$ female $)$, region of birth $(0=$ Asia; $1=$ Africa $)$, having health insurance $(0=$ yes; $1=$ no), and having a PCP (PCP; $0=$ yes; $1=$ no).

\section{Analysis}

Three sets of analyses were conducted. First, descriptive analyses were performed to provide background information on the sample. Second, we reported the prevalence of HBV and HCV infection by region of birth using the Pearson's chi-square test. Finally, we conducted logistic regression analysis to examine factors associated with LTC for $\mathrm{HBV}$ and $\mathrm{HCV}$ infection. All analyses were performed using IBM SPSS Statistics for Windows, version 26 (IBM Corp., Armonk, N.Y., USA).

\section{Results}

\section{Demographic and Health-Related Characteristics}

The mean (standard deviation) age of participants was 52.5 (15.6) years. Most participants were women (60.8\%). Seventy percent were of Asian background, and $22.6 \%$ of African background. About one-third of the participants had been in the US less than 10 years. Forty-four percent of the participants reported that English was not their primary language. Approximately two-third of the participants were uninsured (65.7\%) and did not have a regular PCP (65.4\%) (see Table 1).

Table 1 Background characteristics of study population from the hepatitis screening in the community, 2016-2019 $(\mathrm{n}=8730)$

\begin{tabular}{|c|c|}
\hline Characteristics & $\mathrm{N}(\%)$ \\
\hline \multicolumn{2}{|l|}{ Sex at birth } \\
\hline Female & $5312(60.8)$ \\
\hline Male & $3418(39.2)$ \\
\hline Age, years (mean $\pm S D$ ), range & $52.54 \pm 15.55,(18-103)$ \\
\hline \multicolumn{2}{|l|}{ Ethnicity } \\
\hline African immigrant & $1970(22.6)$ \\
\hline Asian immigrant & $6125(70.2)$ \\
\hline Black & 139 (1.6) \\
\hline Hispanic & $463(5.3)$ \\
\hline White & $9(0.1)$ \\
\hline Unknown & $24(0.3)$ \\
\hline \multicolumn{2}{|l|}{ Birth region } \\
\hline Africa & $1955(22.4)$ \\
\hline Asia & $6117(70.1)$ \\
\hline Europe & $47(0.5)$ \\
\hline North America & $460(5.3)$ \\
\hline South America & $151(1.7)$ \\
\hline \multicolumn{2}{|l|}{ Years in the US } \\
\hline$<1$ & $573(6.6)$ \\
\hline $1-9$ & 2089 (23.9) \\
\hline $10-19$ & $1555(17.8)$ \\
\hline $20+$ & $1443(16.5)$ \\
\hline Unknown & $3070(35.2)$ \\
\hline \multicolumn{2}{|l|}{ Primary language } \\
\hline English & $2861(32.8)$ \\
\hline Non-English & $3836(43.9)$ \\
\hline Unknown & $2033(23.3)$ \\
\hline \multicolumn{2}{|l|}{ Current health insurance } \\
\hline Yes & 3347 (34.2) \\
\hline No & $6431(65.7)$ \\
\hline \multicolumn{2}{|l|}{ Current health provider } \\
\hline Yes & $3379(34.5)$ \\
\hline No & 6399 (65.4) \\
\hline
\end{tabular}




\section{HBV and HCV Serologic Testing Results}

From 2016 to 2019, 8429 immigrants were screened for HBV infection. Among them, 4.5\% $(n=378)$ were found to be chronically infected and referred to follow-up care. Among the Asian-born subpopulation, 4.8\% $(n=286)$ had a chronic HBV infection, $36.4 \%(\mathrm{n}=2177)$ were vulnerable, and $58.8 \%(\mathrm{n}=3522)$ were protected. Among the African-born subpopulation, $4.8 \%(\mathrm{n}=90)$ were chronically infected, $39.9 \%(\mathrm{n}=752)$ were vulnerable, and $55.3 \%$ $(\mathrm{n}=1411)$ were protected (see Table 2$)$.

From 2017 to 2019, HBI-DC also provided HCV testing to 6410 clients across a total of 194 screening events. Among the 6410 participants who were screened for HCV infection, $3.2 \%(n=204)$ were HCVAb-positive. Within the Asian-born subpopulation, 3.9\% $(\mathrm{n}=169)$ were exposed to HCV, versus $2.1 \%(\mathrm{n}=33)$ among the Africanborn subpopulation $(\mathrm{p}<0.001)$ (see Table 2$)$. Those who were HCVAb-positive with known LTC status had followup PCR testing to confirm HCV RNA presence.

\section{Linkage-to-Care}

Among the 378 individuals who had a positive $\mathrm{HBsAg}$ test, $87.0 \%(\mathrm{n}=329)$ received follow-up care, $12.2 \%$ $(n=46)$ were referred to care but it is unknown whether they attended their first appointment following initial HBV screening, and $0.8 \%(n=3)$ could not be located or had no record of follow-up care (see Fig. 1). In the regression analysis, region of birth and having health insurance were marginally associated with LTC for HBV infection $(p<0.10)$. Since having health insurance and a regular PCP were highly

Table 2 Prevalence of HBV and HCV infection among HBI-DC clients, serviced sites from 2016 to 2019

\begin{tabular}{|c|c|c|c|c|c|c|c|}
\hline & \multirow{2}{*}{$\begin{array}{l}\text { Total screened } \\
\mathrm{N}(\%)\end{array}$} & \multicolumn{5}{|c|}{ Region of birth } & \\
\hline & & Africa N (\%) & Asia N (\%) & Europe N (\%) & North America N (\%) & $\begin{array}{l}\text { South } \\
\text { America N } \\
(\%)\end{array}$ & \\
\hline HBV infection status ${ }^{a}$ & $\mathrm{~N}=8429$ & $\mathrm{~N}=1883$ & $\mathrm{~N}=5985$ & $\mathrm{~N}=42$ & $\mathrm{~N}=387$ & $\mathrm{~N}=132$ & .000 \\
\hline Infected & $378(4.5)$ & $90(4.8)$ & $286(4.8)$ & $0(0)$ & $1(0.3)$ & $1(0.8)$ & \\
\hline Protected & $4717(56.0)$ & $1041(55.3)$ & $3522(58.8)$ & $16(38.1)$ & $96(24.8)$ & $42(31.8)$ & \\
\hline Vulnerable & $3334(39.5)$ & 752 (39.9) & $2177(36.4)$ & $26(61.9)$ & $290(74.9)$ & $89(67.4)$ & \\
\hline $\mathrm{HCV}$ infection status ${ }^{\mathrm{b}}$ & $\mathrm{N}=6410$ & $\mathrm{~N}=1572$ & $\mathrm{~N}=4380$ & $\mathrm{~N}=37$ & $\mathrm{~N}=318$ & $\mathrm{~N}=103$ & .000 \\
\hline HCV exposed & $204(3.2)$ & $33(2.1)$ & $169(3.9)$ & $0(0)$ & $2(0.6)$ & $0(0)$ & \\
\hline
\end{tabular}

a 2016-2019

b2017-2019

Fig. 1 Immigrants screened for HBV infection over a 4-year time period, 2016-2019, in the Washington-Baltimore metropolitan area

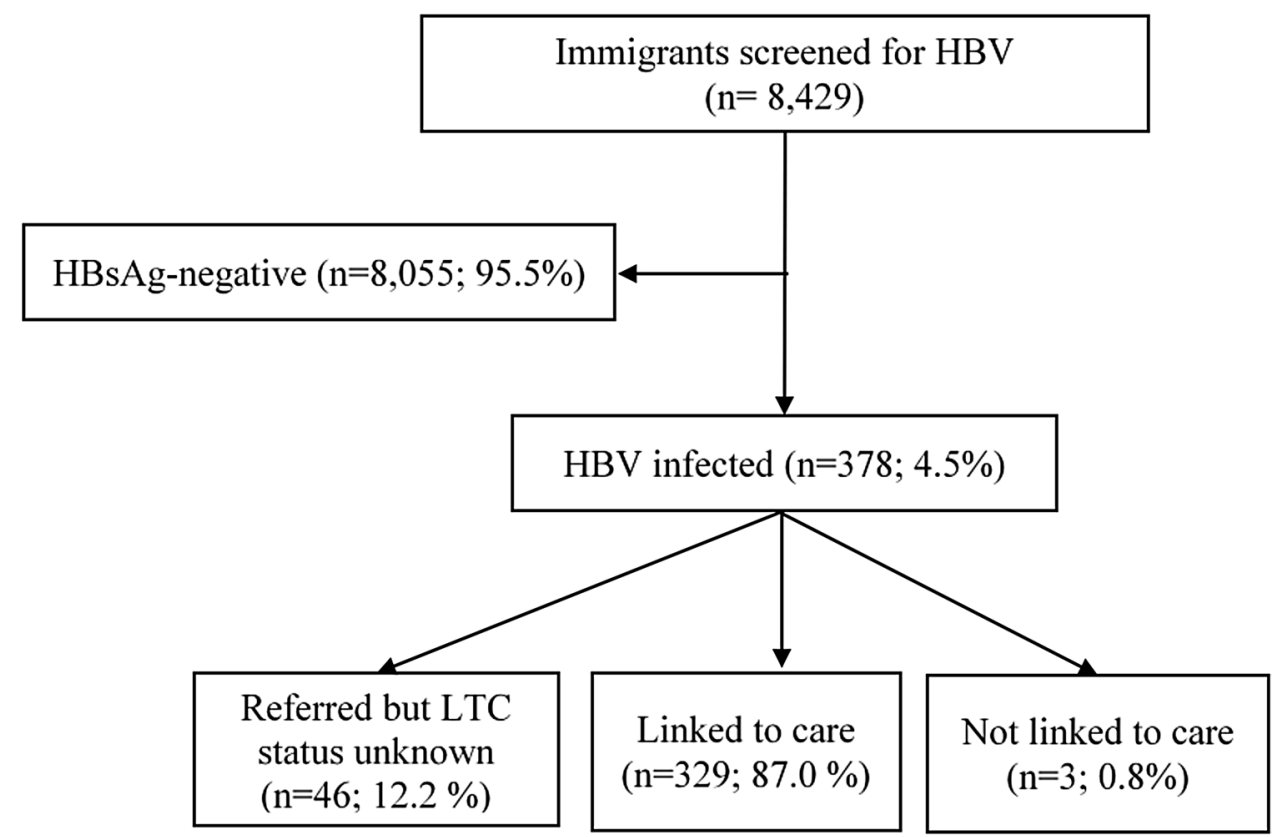


associated $(\mathrm{p}<0.001)$, a new variable was constructed into three group (e.g., neither health insurance nor PCP, either, both). In multivariate regression analysis, those who had neither insurance nor PCP were more likely to have LTC for $\mathrm{HBV}$ infection than those who had either $(\mathrm{aOR}=2.95,95 \%$ CI: 1.32-6.59). African-born immigrants were less likely to have LTC for HBV infection than Asian-born immigrants $(\mathrm{aOR}=0.54,95 \%$ CI: $0.28-1.05, \mathrm{p}=0.069)$ (see Table 3$)$.

Among the 192 individuals who were HCVAb-positive with known LTC status $(n=192), 52.1 \%(n=100)$ had undetected HCV RNA (i.e., "resolved") and 47.9\% $(n=92)$ had PCR-confirmed HCV RNA presence. Of those with confirmed HCV RNA, 52\% ( $n=48)$ were linked to care (see Fig. 2). In multivariate logistic regression, gender was associated with LTC-HCV: females were less likely to LTC-HCV than males (aOR $=0.39,95 \%$ CI: $0.16-0.97)$ (see Table 3$)$.

\section{Discussion}

Viral hepatitis infections such as HBV and HCV continue to affect many around the world, and has become a major public health issue. While there are certain regions that are more affected than others, certain subpopulations in the US also carry this burden of disease with significant morbidity and mortality [13-15]. Immigrants originating from HBV and $\mathrm{HCV}$ endemic countries (with a prevalence of $2.0 \%$ or more) are at a higher risk for HBV infection $[6,16]$ and $\mathrm{HCV}$ infection [17]. Early screening, timely LTC follow-up, and routine monitoring of people at increased risk for chronic $\mathrm{HBV}$ and $\mathrm{HCV}$ infection can further enhance current public health efforts to provide tailored care services to prevent and treat viral hepatitis among immigrants [11]. Because most chronically infected individuals have no symptoms, the only reliable method to diagnose $\mathrm{CHB}$ is with a serologic test for HBsAg. Likewise, the only way to ensure that an individual is protected against HBV is with a serologic test for antiHBs. The availability of those screenings does not guarantee that they are used by those who would benefit the most (i.e., high-risk populations).

Many factors, such as lack of understanding or familiarity with the US health-care system, language barriers, cultural beliefs, and financial scarcity prevent immigrants from fully grasping the implications of their infection and receiving treatment. Foreign-born individuals diagnosed with chronic HBV infection often go years without followup treatment after their initial screening. While treatment for $\mathrm{HBV}$ and $\mathrm{HCV}$ are available, only a small proportion of

Table 3 Logistic regression model for LTC for HBV and HCV infection from 2016 to 2019

\begin{tabular}{|c|c|c|c|c|}
\hline & \multicolumn{2}{|c|}{$\begin{array}{l}\text { LTC for HBV infection }(\mathrm{n}=376)^{\mathrm{a}, \mathrm{c}} \\
(87 \% \text { LTC; } 13 \% \text { no LTC) }\end{array}$} & \multicolumn{2}{|c|}{$\begin{array}{l}\text { LTC for HCV infection }(\mathrm{n}=92)^{\mathrm{b}, \mathrm{c}} \\
(52 \% \text { LTC; } 48 \% \text { no LTC) }\end{array}$} \\
\hline & Unadjusted OR (95\% CI) & Adjusted OR (95\% CI) & Unadjusted OR (95\% CI) & Adjusted OR (95\% CI) \\
\hline Age & $.99(.97-1.02)$ & $.99(.97-1.02)$ & $.98(.95-1.02)$ & $.98(.94-1.02)$ \\
\hline \multicolumn{5}{|l|}{ Gender } \\
\hline Female & $1.38(.75-2.52)$ & $1.40(.76-2.59)$ & $.36(.15-.88)^{*}$ & $.39(.16-.97)^{*}$ \\
\hline Male & 1.00 & 1.00 & 1.00 & 1.00 \\
\hline \multicolumn{5}{|l|}{ Region of birth } \\
\hline Africa & $.55(.29-1.05)^{\mathrm{d}}$ & $.54(.28-1.05)^{\mathrm{d}}$ & $1.30(.43-3.95)$ & $1.13(.31-4.18)$ \\
\hline Asia & 1.00 & 1.00 & 1.00 & 1.00 \\
\hline \multicolumn{5}{|l|}{ Having PCP } \\
\hline No & $1.55(.82-2.93)$ & N/A & $1.46(.47-4.50)$ & $.55(.14-2.10)$ \\
\hline Yes & 1.00 & & 1.00 & 1.00 \\
\hline \multicolumn{5}{|l|}{ Having health insurance } \\
\hline No & $1.78(.96-3.30)^{\mathrm{d}}$ & N/A & $1.50(.32-7.11)$ & $1.87(.23-12.49)$ \\
\hline Yes & 1.00 & & 1.00 & 1.00 \\
\hline \multicolumn{5}{|l|}{ PCP*health insurance } \\
\hline Neither & $2.90(1.31-6.42)^{*}$ & $2.95(1.32-6.59)^{*}$ & N/A & N/A \\
\hline Either of PCP or insurance & 1.00 & 1.00 & & \\
\hline Both & $1.77(.72-4.35)$ & $1.87(.75-4.71)$ & & \\
\hline
\end{tabular}

${ }^{*} \mathrm{p}<.05$

${ }^{a}$ HBV LTC data only available from 2016 to 2019

${ }^{b} \mathrm{HCV}$ LTC data only available from 2017 to 2019

${ }^{\mathrm{c}}$ Not included those from Europe and Americas $(\mathrm{n}=2)$

${ }^{\mathrm{d}} \mathrm{p}<.10$ 


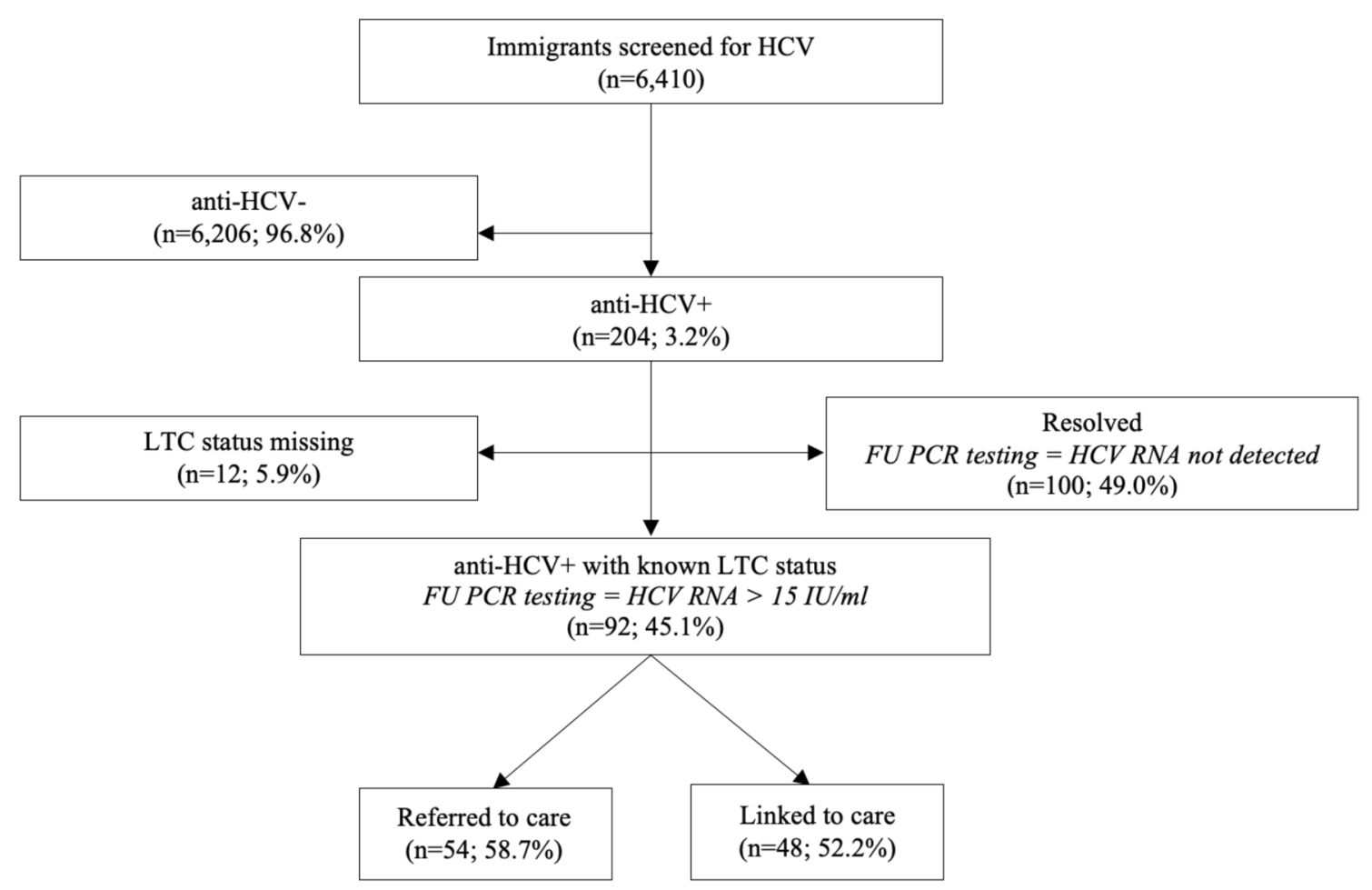

Fig. 2 Immigrants screened for HCV infection over a 3-year time period, 2017-2019, in the Washington-Baltimore metropolitan area

individuals with $\mathrm{HBV}$ or $\mathrm{HCV}$ infection receive treatment. In the primary care setting, management of patients following diagnosis is not optimal, as many PCPs are not familiar with the management and treatment of HBV and HCV [18-20]. Moreover, although they may be referred, patients frequently do not see a specialist [13]; and unfortunately, not all patients who qualify for treatment can begin treatment.

Early detection of chronic hepatitis infection by screening, with prompt and timely LTC, and strong surveillance infrastructure has the potential to prevent the infection from worsening. HBI-DC implemented the CDC's HBV screening and services recommendations [8] to link to care $87.0 \%$ and $52.2 \%$ of clients with chronic HBV infection and HCV infection, respectively. Crucial to the needs of the majority of their clients-who did not have health insurance or access to a PCP - these services included community screening events, patient navigation, use of electronic medical records, and provider education and feedback. Implementing a range of concurrent strategies was vital to HBI-DC ability to effectively reach and provide appropriate and affordable care to the different immigrant populations that they served [21]. Results from the present study are comparable to, if not exceed, the proportion of LTC among refugees with CHB after first diagnosis in the US as described in prior studies which ranged from 29 to $53 \%$ [10, 12, 21-28].

Aligning with findings and recommendations from prior studies [10], a key facilitator to HBI-DC's success in implementing a screening and LTC program that yielded the aforementioned high screening and LTC rates was the engagement of bilingual care navigators. Immigrants require providers, services, and resources that are culturally- and linguistically-competent in order to ensure that they are successfully linked to care [10]. The HBI-DC care navigators' cultural understanding and linguistic skills, along with their ties to public health services, allowed them to tackle challenges such as fear and confusion about the health care system. Successful screening and referral for LTC alone was not sufficient, immigrants required guidance and assistance to ensure that referrals resulted in scheduled and completed appointments. Care navigators made numerous attempts to contact and persistently engaged in communications with individuals with no access to care to ensure that they are linked to care by arranging transportation, rescheduling appointments, and providing support and/or referring the clients as needed. This shows the value of bilingual and culturally-competent providers in helping community members understand the importance of follow-up treatment and address obstacles to receiving care. Another key component of HBI-DC's successful program is the provision of testing, vaccination, and treatment for hepatitis $\mathrm{B}$ and $\mathrm{C}$ through an existing network of health care providers [10].

As demonstrated by our findings, these services were well utilized by individuals who did not have access to care: they were more likely to be linked to care. On the other hand, 
individuals who indicated that they had a PCP or health insurance were less likely to be linked to care. Individuals with access to care are encouraged to make an appointment with their PCP for follow-up. This underscores the importance of providing these LTC services to all immigrants regardless of their access to care. Our finding contributes to the current body of evidence suggesting that $\mathrm{HBV} / \mathrm{HCV}$ screening in the community setting and subsequent patient navigation can enhance progression through the hepatitis care continuum.

\section{Limitations}

There are several limitations to our study. From 2016 and part of 2017, confirmatory tests were not performed for all clients who had a positive HCV antibody test; therefore, the presumptive $\mathrm{HCV}$ infection rate was used instead of the confirmed HCV infection rate. The data being presented was collected from individuals who are residents of a major metropolitan area; specific challenges may exist when attempting to provide LTC services in more rural areas. The intake form used to collect demographic information about clients was not consistent from year to year, therefore, not all data points were collected from all participants (e.g., primary language). Individuals who were lost during follow-up may have also become more mobile and less likely to be linked to treatment. Still, had these individuals actually received care (whether it was within or outside of the Washington-Baltimore metropolitan area), an additional challenge was not being able to track and document LTC activities among some of these individuals who may have changed their contact information post-screening.

\section{New Contribution to the Literature}

Early screening, timely LTC follow-up, and routine monitoring of people at increased risk for chronic $\mathrm{HBV}$ and $\mathrm{HCV}$ infection can result in better liver cancer outcomes for impacted populations nationwide. Our analysis provides further understanding of the associated characteristics that impact LTC among those living with HBV and HCV. To enhance current public health efforts to prevent and treat viral hepatitis among immigrants, it is essential to equally provide HBV and HCV LTC support to all immigrants from endemic countries regardless of their access to care.

\section{Conclusion}

Effective LTC services depend on access to safe, accessible healthcare, which is important for improving outcomes in the US for individuals with chronic hepatitis infections. Our findings showed that lack of health insurance or a PCP were not found to be barriers to linking $\mathrm{HBV}$ and $\mathrm{HCV}$ patients to care. Access to care was an important predictor for LTC and notably, individuals with no PCP or health insurance were more likely to be linked to care. This adds to the body of evidence suggesting that it is essential to equally provide $\mathrm{HBV}$ and HCV LTC support to all immigrants from countries with high prevalence regardless of access to care. Furthermore, study findings also reinforced that optimal HBV and HCV screening and LTC can be achieved through targeted interventions, and geographically-focused collaborations with health departments, community-based organizations, and local clinics.

Supplementary Information The online version contains supplementary material available at https://doi.org/10.1007/s10903-022-01327-7.

Acknowledgements We would like to thank the Hepatitis B Initiative of Washington, DC (HBI-DC) for providing the data that supported this work. Free community-based health screenings organized by HBI-DC are supported by DC Department of Health-HIV/AIDS, Hepatitis, STD, and TB Administration (HAHSTA), DC Mayor's Office on African Affairs, DC Mayor's Office on Asian and Pacific Islander Affairs, George Washington University, Gilead Sciences, Hep B United, Maryland Department of Health, Minority Health and Health Disparities, Maryland Department of Health, Viral hepatitis Division, Northern VA Community Foundation, Office of Minority Health, Ruth H Kuo \& Rhoda How Memorial Foundation, University of Maryland, and individual donors.

Author Contributions All authors contributed to the study conception and design. All authors have reviewed and approved the manuscript for submission.

Funding This work was funded by the Office of Minority Health, U.S. Department of Health and Human Services (CPIMP191177).

\section{Declarations}

Conflict of interest All authors certify that they have no affiliations with or involvement in any organization or entity with any financial interest or non-financial interest in the subject matter or materials discussed in this manuscript.

Ethical Approval All human participants were treated in accord with the Principles of the Ethical Practice of Public Health of APHA, gave their informed consent to participate, and the study was approved by the George Washington University Institutional Review Board (NCR191911).

Informed Consent Informed consent was obtained from all individual participants included in the study. 


\section{References}

1. Rawla P, Sunkara T, Muralidharan P, Raj JP. Update in global trends and aetiology of hepatocellular carcinoma. Contemp Oncol (Pozn). 2018;22(3):141-50.

2. World Health Organization. Global Hepatitis Report, 2017. 2017. https://www.who.int/hepatitis/publications/global-hepatitis-repor t2017/en. Accessed 15 Oct 2020.

3. World Health Organization. Hepatitis B Fact Sheet. 2020. https:// www.who.int/news-room/fact-sheets/detail/hepatitis-b. Accessed 15 Oct 2020

4. American Cancer Society. Cancer Facts \& Figures 2020.2020. www.cancer.org/research/cancerfactsstatistics/cancerfacsfigur e2014/index. Accessed on 15 Oct 2020.

5. Rahib L, Smith BD, Aizenberg R, Rosenzweig AB, Fleshman JM, Matrisian LM. Projecting cancer incidence and deaths to 2030: the unexpected burden of thyroid, liver, and pancreas cancers in the United States. Cancer Res. 2014;74(11):2913-21.

6. Kowdley KV, Wang CC, Welch S, Roberts H, Brosgart CL. Prevalence of chronic hepatitis B among foreign-born persons living in the United States by country of origin. Hepatology. 2012;56(2):422-33.

7. Institute of Medicine (US) Committee on the Prevention and Control of Viral Hepatitis Infection. Hepatitis and Liver Cancer: a National Strategy for Prevention and Control of Hepatitis B and C. Washington, DC: National Academies Press; 2010.

8. LeFevre ML, U.S. Preventive Services Task Force. Screening for hepatitis B virus infection in nonpregnant adolescents and adults: US Preventive Services Task Force recommendation statement. Ann Intern Med. 2014;161(1):58-66.

9. American Association for the Study of Liver Diseases and Infectious Diseases Society of America (ASLD-IDSA). Recommendations for testing, managing, and treating hepatitis C. http://www. hcvguidelines.org. Accessed on 6 June 2020.

10. Ramirez G, Cabral R, Patterson M, Schoenbachler BT, Bedell D, Smith BD, Vellozzi C, Beckett GA. Early identification and linkage to care for people with chronic HBV and HCV infection: the HepTLC Initiative. Public Health Rep. 2016;131(2):5-11.

11. Harris AM, Link-Gelles R, Kim K, Chandrasekar E, Wang S, Bannister N, Pong P, Chak E, Chen MS, Bowlus C, Nelson NP. Community-based services to improve testing and linkage to care among non-U.S.-born persons with chronic hepatitis B virus infection-three U.S. programs, October 2014-September 2017. MMWR Morb Mortal Wkly Rep. 2018;67(19):541-6.

12. Young J, Payton C, Walker P, et al. Evaluation of a program to improve linkage to and retention in care among refugees with hepatitis B virus infection-three U.S. cities, 2006-2018. MMWR Morb Mortal Wkly Rep. 2020;69:647-50.

13. Hu DJ, Xing J, Tohme RA, Liao Y, Pollack H, Ward JW, Holmberg SD. Hepatitis B testing and access to care among racial and ethnic minorities in selected communities across the United States, 2009-2010. Hepatology. 2013;58(3):856-62.

14. Kim WR. Epidemiology of hepatitis B in the United States. Hepatology. 2009;49(5 Suppl):S28-34.

15. Wasley A, Kruszon-Moran D, Kuhnert W, Simard EP, Finelli L, McQuillan G, Bell B. The prevalence of hepatitis B virus infection in the United States in the era of vaccination. J Infect Dis. 2010;202(2):192-201.
16. Pollack HJ, Kwon SC, Wang SH, Wyatt LC, Trinh-Shevrin C, AAHBP Coalition. Chronic hepatitis B and liver cancer risks among Asian immigrants in New York City: results from a large, community-based screening, evaluation, and treatment program. Cancer Epidemiol Biomarkers Prev. 2014;23(11):2229-39.

17. Greenaway C, Ma AT, Kloda LA, Klein M, Cnossen S, Schwarzer $\mathrm{G}$, Shrier I. The seroprevalence of hepatitis $\mathrm{C}$ antibodies in immigrants and refugees from intermediate and high endemic countries: a systematic review and meta-analysis. PLoS ONE. 2015;10(11):e0141715.

18. Peksen Y, Canbaz S, Leblebicioglu H, Sunbul M, Esen S, Sunter AT. Primary care physicians' approach to diagnosis and treatment of hepatitis B and hepatitis C patients. BMC Gastroenterol. 2004;4:3.

19. Veldhuijzen IK, Mehlika Toy M, Hahné SJM, De Wit GA, Schalm SW, de Man RA, Richardus JH. Screening and early treatment of migrants for chronic hepatitis B virus infection is cost-effective. Gastroenterology. 2010;138(2):522-30.

20. Ku KC, Li J, Ha NB, Martin M, Nguyen VG, Nguyen MH. Chronic hepatitis B management based on standard guidelines in community primary care and specialty clinics. Dig Dis Sci. 2013;58(12):3626-33.

21. Ortiz E, Scanlon B, Mullens A, Durham J. Effectiveness of interventions for hepatitis $B$ and $C$ : a systematic review of vaccination, screening, health promotion and linkage to care within higher income countries. J Community Health. 2020;45(1):201-18.

22. Raines-Milenkov A, Felini M, Baker E, et al. Hepatitis B virus awareness, infection, and screening multiethnic community intervention for foreign-born populations. J Commun Health. 2021;46:967-74.

23. Trooskin SB, Poceta J, Towey CM, et al. Results from a geographically focused, community-based HCV screening, linkage-to-care and patient navigation program. J Gen Intern Med. 2015;30(7):950-7.

24. Cachay ER, Hill L, Wyles D, Torriani FJ, Ballard C, Colwell B. The hepatitis $\mathrm{C}$ cascade of care among HIV-infected patients following diagnosis of HCV infection [Abstract 672]. Top Antivir Med. 2014;22(e-1):335.

25. Yehia BR, Schranz AJ, Umscheid CA, Lo Re V III. The treatment cascade for chronic hepatitis $C$ virus infection in the United States: a systematic review and meta-analysis. PLoS ONE. 2014;9(7):e101554.

26. Falade-Nwulia O, Mehta SH, Lasola J, et al. Public health clinicbased hepatitis $\mathrm{C}$ testing and linkage to care in baltimore. J Viral Hepatitis. 2016;23(5):366-74.

27. Perumalswami PV, Factor SH, Kapelusznik L, et al. Hepatitis Outreach Network: a practical strategy for hepatitis screening with linkage to care in foreign-born communities. J Hepatol. 2013;58(5):890-7.

28. Yeo YH, Nguyen MH. Current gaps and opportunities in HBV prevention, testing and linkage to care in the United States-a call for action. Aliment Pharmacol Ther. 2021;53(1):63-78.

Publisher's Note Springer Nature remains neutral with regard to jurisdictional claims in published maps and institutional affiliations. 